ECCOMAS

Proceedia

\author{
COMPDYN 2017 \\ $6^{\text {th }}$ ECCOMAS Thematic Conference on \\ Computational Methods in Structural Dynamics and Earthquake Engineering \\ M. Papadrakakis, M. Fragiadakis (eds.) \\ Rhodes Island, Greece, 15-17 June 2017
}

\title{
SIMULATED DESIGN PROCEDURE FOR AN IMPROVED SEISMIC VULNERABILITY ASSESSEMENT OF EXISTING RC BRIDGES
}

\author{
P. Ceresa ${ }^{1}$, and L. Marziali ${ }^{2}$ \\ ${ }^{1}$ Institute for Advanced Studies, IUSS Pavia \\ Piazza della Vittoria 15, 27100 Pavia, Italy \\ e-mail: paola.ceresa@iusspavia.it \\ ${ }^{2}$ UME School, Institute for Advanced Studies, IUSS Pavia \\ Piazza della Vittoria 15, 27100 Pavia, Italy \\ e-mail: marziali.lorenzo@gmail.com
}

Keywords: simulated design, existing bridges, $\mathrm{RC}$ bents, seismic response

\begin{abstract}
This research work proposes the development of a simplified method for simulated design of existing reinforced concrete (RC) motor-way bridges. Given the fragmentary availability of data, the simulated design procedure should provide information about the reinforcement of bent members in order to proceed with the seismic response assessment of the whole bridge. The developed methodology should be as simple as possible in order to be suitable for large scale seismic vulnerability assessment of the Italian roadway bridge stock. Nevertheless, the methodology should be general in order to take into account the evolution of both construction technologies and regulations within a time window of 50 years, from 1940 to 1990, the most productive period concerning the construction of Italian roadway bridge stock. The validation of the method has been carried out through the comparison of the available executive design documentation of several existing bridges with the corresponding simulated design results, quantifying the discrepancy. Finally, the seismic response of both the existing structure and the "simulated" one have been analyzed by means of non-linear static and dynamic analyses, in order to estimate the influence of such discrepancy on the assessment of the bridge response and, mainly, to evaluate its influence on the large scale seismic vulnerability assessment.
\end{abstract}




\section{BACKGROUND AND MOTIVATION}

The assessment of the seismic response of existing structures requires an adequate level of information concerning the geometry of structural members and connections as well as their material properties. Collecting a sufficient level of knowledge of the structure is indeed a preliminary and fundamental step in the seismic response analysis [1] [2]. The required information should be gathered through the review of the executive design documentation, when available, in combination with in-situ surveys and material tests. Given that the aforementioned procedure is likely to be quite expensive in terms of resources and time (especially for those structures whose executive design documentation is not available), the simulated design should be considered as an alternative solution. The simulated design is particularly suitable for large scale seismic risk assessment, with the aim of providing a preliminary estimation of the seismic vulnerability and an order of priority for further analysis and retrofit interventions, when a large sample of structures has to be assessed.

This research work focuses on the development of a simple but general procedure for the simulated design of existing reinforced concrete (RC) bridges designed in Italy from 1940 to 1990. The target of the proposed procedure for simulated design is the estimation of the amount and the configuration of longitudinal and transversal steel reinforcement in RC bent members, knowing the member geometry and the material properties as input data. The procedure should be as simple and general as possible in order to be suitable for large-scale assessment, without neglecting the evolution of both construction technologies and regulations within the period of interest. The development of the procedure is based upon the contemporary regulatory framework concerning bridge design and seismic design, which provide information about the external actions to be considered for the design. A review of several contemporary academic manuals about bridge design ([3]:[12]) have been also considered as a fundamental reference on this matter. The contemporary regulation concerning the design of $\mathrm{RC}$ bridges and buildings has been considered for material classification and for steel bar detailing.

\section{EVOLUTION OF THE ITALIAN REGULATIONS IN THE 20TH CENTURY}

The design of RC motorway-bridges has been subjected to regulations dedicated to bridges, but also to prescriptions which are not specifically related to bridges. From a comprehensive literature review carried out in this work, it can be stated that the Italian regulatory framework consists of three main areas:

a. Prescriptions for structural design of bridges $([13] \div[19])$;

b. Prescriptions for structural design of buildings located in seismic areas $([20] \div[22])$;

c. Prescriptions for structural design of RC buildings ([23]:[26]).

The above mentioned regulations provide information on both the external loads and actions, and the detailing prescriptions the designer should have considered in the project. A detailed description of the most important aspects of the evolution of the Italian regulations is provided in [27].

\section{SIMPLIFIED METHOD FOR THE SIMULATED DESIGN OF BRIDGES}

The target of the simulated design of existing structures is to provide information about those characteristics not directly obtainable from in-situ surveys, such as member reinforcement or joints detailing, in the cases when the design documentation is not available. Simulated design should be preferred to surveys or documentation review when the seismic response assessment has to be carried out for a large number of homogeneous structures and the effort of the surveys is not affordable. Design output should be as closer as possible to the 
actual configuration of the existing structure in order to proceed with an effective assessment of its seismic response. The proposed method focuses on substructure details (steel reinforcement configuration) for motorway-bridges with continuous or discontinuous deck, designed between 1940 and 1990. The methodology is based on the elaboration of data such as age, location and geometry of the structure and mechanical properties of materials, according to the appropriate design prescriptions inferred from the contemporary regulation, the technical literature and the design reports on the available cases of study.

\subsection{Main assumptions}

For the sake of simplicity, the design procedure relays upon assumptions about structure geometry, distribution of forces among structural members and nodal degrees of freedom. Such assumptions are considered to have negligible impact on design results. Furthermore, given that most of the data about material properties is usually missing, the latter need to be derived from the review of the contemporary regulatory framework, technical literature and available design reports. This review represents also a reference for several assumptions and simplifications concerning the design procedure, which allows the method to be as general as required for large scale application but consistent with contemporary construction practice and technologies.

One of the most important simplifications adopted in the proposed method is to consider each pier as if it was not connected to the rest of the structure. An ideal superstructure portion including half of each tributary span length gives the load on the piers. This implies neglecting the eventual stiffness irregularity along the structure, due to differences in bent heights and to abutments stiffness. In case of regular and irregular bridges with discontinuous superstructure, in which relative rotation between adjacent girders is weakly inhibited, this assumption is fairly consistent with the actual transversal behaviour of the structure. Also the transversal behaviour of regular bridges with continuous superstructure is compatible with such assumption. On the other hand, the longitudinal behaviour of irregular bridges with continuous or discontinuous superstructure is captured with limited accuracy, since in this case all the bents are constrained to the same top displacement. However, it should be pointed out that discontinuous superstructure is the main representative among existing motorway bridges.

Then the bearing devices between the super- and sub-structure are assumed to transfer the entire lateral load to the substructure, including the case of merely frictional bearing capacity [2] [28]. This is considered to be consistent with the requirement for structure serviceability prescribed for the design level of loads.

Furthermore, it is assumed that the foundations do not suffer any stiffness loss for the design level of loads and thus the substructure base is assigned to be fully fixed.

Superstructure torsional and flexural stiffness is assumed to be negligible with respect to substructure flexural stiffness, implying bent top is assigned free-end boundary conditions in both longitudinal and transverse direction. Once more, this ensures a better fit to discontinuous superstructure bridges behaviour than to continuous ones. Nevertheless, as continuous superstructure is usually associated to large span lengths, the assumption is considered to be acceptable for both bridges categories.

The method refers to contemporary regulations for what concerns external loads, particularly for horizontal actions (wind, braking vehicles and earthquake) combined with permanent and moving gravity loads. Additionally, multiple configurations of moving loads are considered in order to determine the more unfavourable set of actions (in terms of vertical and horizontal forces and flexural moments) transmitted from superstructure to bent top. Vertical loads are thus assigned a longitudinal and a transversal eccentricity, standing respectively for 
the eventual non-symmetric distribution of moving loads across the deck width and the bearing device eccentricity (in case of bridges with discontinuous superstructure).

Seismic actions are included in the design procedure within the equivalent static analysis framework. The modal analysis framework, included in national provisions from 1975, is not included in the design procedure, because it is considered to be incompatible with the desirable level of simplicity. Moreover, the modal analysis is unlikely to have found widespread application for bridge seismic design within the period of interest due to limited available computational tools.

According to the framework of provisions for bridges, the design method considers two conventional loading directions: longitudinal and transversal with respect to the bridge deck. A set of actions is assigned to each conventional direction, including the corresponding vertical and horizontal forces and bending moment, to be applied at bent top. When the local reference system of the bent does not coincide with the one of the deck, the sets of actions are provided referring to the former one. Deformations and forces distribution among the pier members is estimated by means of bi-dimensional elastic frame models, one for each conventional loading direction. It should be pointed out that the axial deformability of the members is neglected. This leads to a loss of accuracy in the estimation of axial actions within the members, in particular for framed substructures. In these structures, assuming no member axial deformability implies that no vertical displacement is captured at the frame nodes and, thus, the axial actions induced in vertical members by the external moment applied to bent-top cannot be properly estimated.

Section detailing design and verification are performed by means of the allowable stress method, independently from the year of design of the bridge, since this method was used in the time window of reference. The section is not verified for the bi-axial bending condition, but only for the two corresponding uniaxial components.

Lateral instability verifications are considered only for bridges designed after 1972 and the member effective length is related to the boundary conditions and the height of the piers.

\subsection{Proposed methodology}

The simulated design method is organized into four main steps, namely:

- Input;

- Estimation of external actions transmitted to bent top;

- Estimation of internal actions in bent members;

- Design and verification of steel reinforcement.

Each step is described in the next subsections.

\section{Input}

The year when the executive design of the bridge was redacted is one of the fundamental input information, as it allows the design process to be related to the corresponding regulatory, scientific and technological context. Also the location, in terms of municipality, distance from the coast and altitude, is an important input information, for an adequate estimation of seismic and wind actions, in accordance with the specific regulation.

Sufficiently detailed information about the geometrical characteristic of the structure is also needed. The width and the span-lengths of the deck are the minimum required information about the superstructure; all the other parameters, if not available, could be obtained by a combination of those basic data with the road traffic class (i.e. motorway or not). In particular, superstructure height and weight could be related to its span-length; while the eventual presence of pedestrians sidewalks is easily inferable from the traffic class of the road. The geo- 
metrical configuration of the bearing devices, both in terms of their height above the bent capbeam and eccentricity, is required for an accurate estimation of the external actions transmitted to the bent top. Information about the bearing height, if unavailable, could be related to the year of the executive design: the employment of polymeric bearings with reinforcing steel plates can be excluded for bridges designed before 1971 (because of the lack of regulations on the subject) and friction supports employing relatively thin rubber layers are considered to be quite widespread for those bridges. Information about the longitudinal eccentricity of bearings, if not available, could be related to the longitudinal dimension of the bent cap-beam.

The geometrical characteristics of the bents should be as detailed as possible. Fundamental information are the sectional typology and the dimensions of both columns and beams. A standard input format have been adopted for bent geometry, according to which the former must be defined as an assembly of segments. The data assigned to each segment can be summarised as follows: height, sectional geometry and sectional multiplicity both in longitudinal and transversal direction. The sectional geometry is represented by means of the minimum required number of parameters in order to describe it accurately. The sectional multiplicity parameter allows multi-column bents or spatial-frame bents to be taken into account by the input format.

Information on the material properties, such as characteristic concrete cubic strength and the steel yielding stress, should be also provided for a more accurate simulation of the design of the section detailing. It has to be noted that concrete quality results to have a great influence on detailing simulation, especially for massive bents containing the minimum prescribed steel percentage and designed before 1972, when that percentage was related to the sole member sectional area necessary to resist purely axial loads.

For bridges designed before 1960, if there are no information on the mechanical properties of materials, the simulated design procedure refers to the acceptability criteria for concrete and steel provided in R.D. n.2229 [23]. For bridges designed between 1960 and 1970, if the information is not available, the procedure assigns conventional mechanical properties according to the statistical mean values provided in [29] [30] for concrete and steel bars employed for RC structures during that time window of reference. For bridges designed after 1970, in absence of detailed information, the simulated design procedure refers to the acceptability criteria for steel provided in D.M. 1972 and D.M. 1974 [31] [32]. If the class of steel is unknown, the procedure employs the steel class FeB 38 with the corresponding minimum mechanical properties. Concrete characteristic compressive strength is assumed to be $\mathrm{R}_{\mathrm{ck}}=25$ $\mathrm{MPa}$, if no different information is provided, in order to be conservative with respect to the available statistical data provided in [29].

\section{Estimation of external actions transmitted to bent top}

The actions transmitted to the top of each pier are grouped in a vector, named $\mathrm{A}_{\text {ext,k}}$, containing five elements, for each considered load combination $\mathrm{k}$ : the vertical force $\mathrm{N}$, two horizontal forces $\mathrm{V}_{\mathrm{L}}$ and $\mathrm{V}_{\mathrm{T}}$, acting in longitudinal and transversal direction respectively, and two flexural moments $\mathrm{M}_{\mathrm{L}}$ and $\mathrm{M}_{\mathrm{T}}$ acting around transversal and longitudinal axis, respectively.

According to code provisions, the following sources of external actions on the top of the pier have been included in the procedure: i) structural self-weight and permanent loads; ii) moving loads and their dynamic effects; iii) wind; iv) earthquake (EQ); v) deformations (e.g. shrinkage, pre-compression, thermal excursions). The prescribed combinations, with very small differences between different regulations, are:

1. Structural and permanent loads + wind + deformations;

2. Structural and permanent loads + moving loads + wind (reduced) + deformations;

3. Structural and permanent loads + moving loads (reduced) + EQ + deformations. 
Each set of external forces, $A_{\text {ext,k}}$, is then rearranged in two independent vectors, $A_{\text {ext,dir,k}}$, defined for each direction $\operatorname{dir}$ ( $\operatorname{dir}=1,2$ where 1 stays for the longitudinal direction and 2 for the transversal direction) and load combination $k$ (Figure 1).

\section{Estimation of internal actions in bent members}

The target of the current design step is to provide different sets of vectors $A_{\text {int }}$, collecting internal member actions at the sections of interest, for each set of external forces $A_{\text {ext,dir,k}}$. Such a vector can be expressed, for each direction dir, load combination $k$ and member section $m$. The internal actions, for each member section of interest, are estimated by means of elastic analysis of planar frames. The analysis takes into account external actions $\mathrm{A}_{\mathrm{ext}, \mathrm{dir}, \mathrm{k}}$, together with pier members self weight (Figure 1). Each set of member internal forces obtained for pier columns, expressed as vector $A_{\text {int,dir,k,m }}$, is rearranged in two independent vectors:

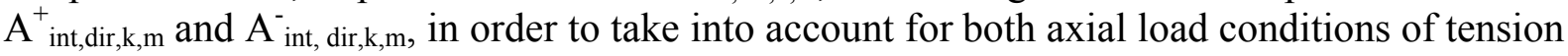
and compression induced by reversal lateral loading. These vectors collect all possible configurations of the internal actions for each considered loading combination and direction and are thus appropriate for section reinforcement design and verification.
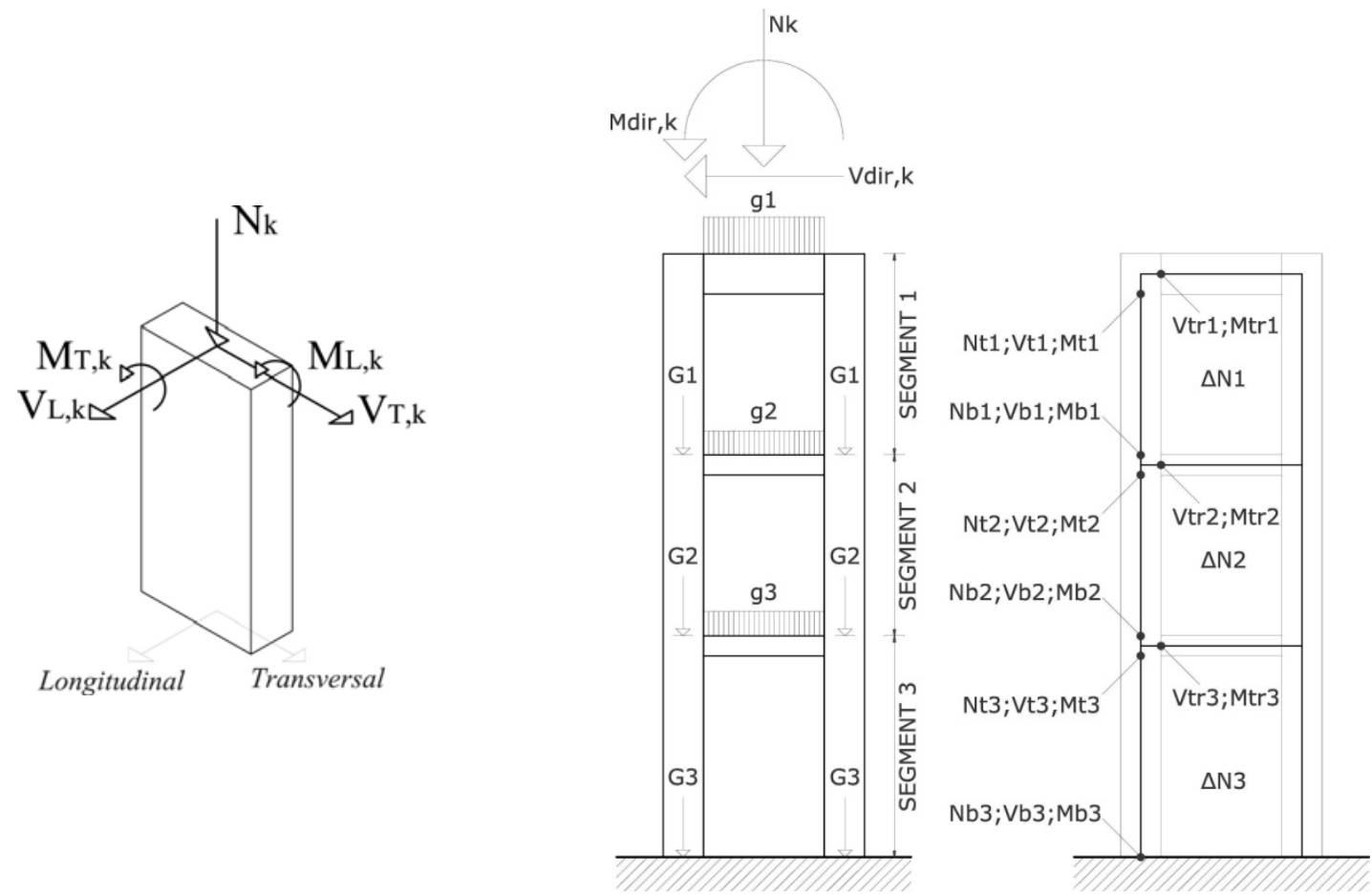

Figure 1: External actions transmitted to a generic bent (left) and internal actions for a generic bent (right)

\section{Design and verification of steel reinforcement}

Knowing the internal actions, the longitudinal and transversal reinforcement bars are designed with the allowable stress method according to the design prescriptions of the time and being compatible with the geometrical dimensions of the section of reference.

The design of longitudinal reinforcement configuration takes into account the executive prescriptions provided by the contemporary regulation for RC design. In particular, the minimum and maximum acceptable bar diameter as well as the minimum bar spacing and concrete cover are some of the restrictions to be observed for section rebar detailing.

According to the regulation, a minimum standard configuration of transversal reinforcement should be assigned to all column and beam members. For what concerns the bar diameter, a minimum of $6 \mathrm{~mm}$ is to be adopted and no restrictions are specified as an upper limit. 
The simulated design starts assuming the minimum amount of reinforcement prescribed in the code of reference. When the minimum prescribed reinforcement is not sufficient for the verification of the section, it is progressively increased until the material stresses remain below the acceptable limits.

\section{VALIDATION}

In order to estimate the accuracy of the proposed method, the simulated design procedure has been applied to several existing bridges. For such bridges, sufficient information had been collected to check whether the results of simulated procedure are accurate. Section details, such as the amount and spacing of longitudinal and transversal reinforcements, have been regarded as the main terms of comparison for accuracy estimation. The internal actions, if available in the documentation, have been also compared.

Within the considered case-studies, ten bridges, grouped according to their sub-structural type, are the focus of the validation (Figure 2):

- Bridges with wall-type substructure;

- Bridges with framed substructure;

- Bridges with single-pier substructure.

Considering the group of the bridges with wall-type substructure, five bridges over the River Adige, located in Trento District and designed between 1961 and 1981, are considered (Avio, 1961; Faedo, 1962; Trento, 1963; Nomi, 1976; Rovereto, 1981). All these bridges present the same structural typology, consisting of a constant span-length discontinuous deck simply supported on a regular substructure. The latter is fixed at the base by means of pile foundations. The only exception is the bridge located in Rovereto (Trento) in which the first wall is fixed to a pile-supported foundation; the other walls have drilled shaft foundations reaching different depths. This group of bridges allowed to investigate the accuracy of the simulated design procedure for structures designed in different periods and, thus, according to different provisions.

Two are the bridges belonging to the group of bridges with framed substructure. They were designed before 1950. Even if they have the same substructure typology and member sectional geometry, the two structures are very dissimilar to each other because of the traffic level and the bents height. The first bridge over the Adige river in Trento was designed in 1943 and is supported on single-level frames being $5.3 \mathrm{~m}$ height. The second is the viaduct Rio Torto in Castiglione dei Pepoli (Bologna) which is supported on multi-level frames of variable heights ranging between $13.8 \mathrm{~m}$ and $41.35 \mathrm{~m}$. This allows the accuracy of the simulated design procedure to be investigated for the same sectional geometry for two different conditions.

Three viaducts, located in Southern Italy and designed between 1965 and 1988, belongs to the third group considered for the validation - the bridge "Vose" in Picerno (Potenza), designed in 1965; the viaduct "La Rossa" in Vietri di Potenza (Potenza), 1971; the viaduct "Egolo" in Caltagirone (Catania), 1988. All these bridges present the same structural typology, consisting of a constant span-length discontinuous deck simply supported on an irregular substructure. A minor variation of this scheme is represented by the viaduct "Vose" in Picerno (Potenza), which has a slightly curved deck, and by viaduct "Egolo" whose span-length is not constant. The section geometry of the pier is hollow rectangular in the first two cases and hollow circular in the third case. This group of bridges allowed the accuracy of simulated design procedure to be investigated for structures with different sectional geometry and designed according to different provisions. 


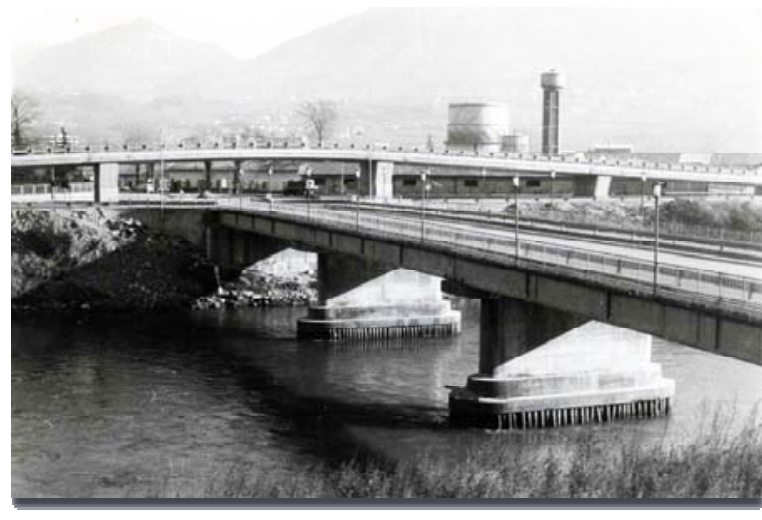

(a)

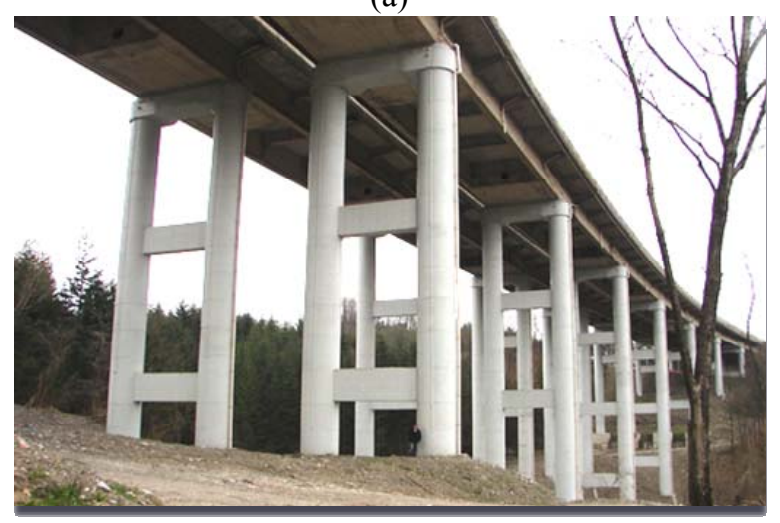

(c)

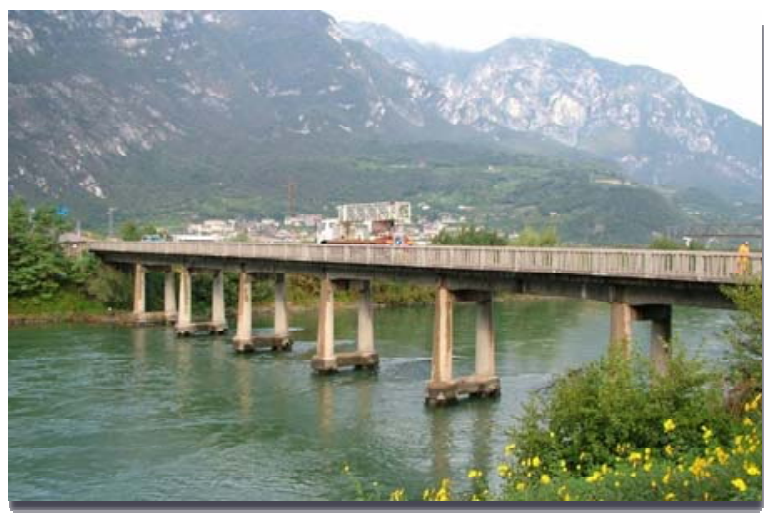

(b)

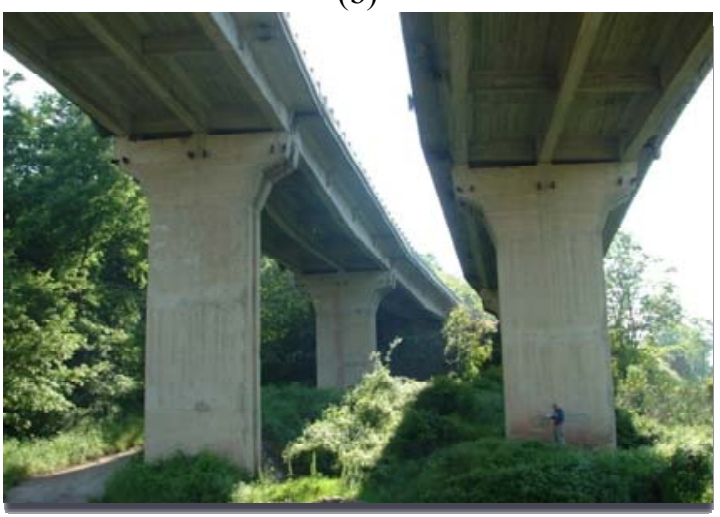

(d)

Figure 2: Some of the RC bridges considered in the validation process. Bridges over the Adige river, Trento, 1962 (a) and 1943 (b). Viaduct over the river Rio Torto, Roncobilaccio (Bologna), 1950 c). Viaduct "Vose", Picerno (Potenza), 1965 d).

The focus of the validation is the evaluation of the discrepancy of the results in terms of computed reinforcing bars with respect to the actual reinforcement configuration in the existing structures, as reported in the available executive design documentation. A discrepancy of $30 \%$ has been considered as an acceptability criterion for the validation, taking into account that the proposed methodology should be applied in large-scale assessment evaluations.

The procedure demonstrated to have a significant variability with the substructure typology for what concerns the level of accuracy in the estimation of both longitudinal and transversal reinforcement, although for most of the considered case studies, a better level of accuracy is achieved for the longitudinal reinforcement with respect to the transversal one. On the other hand, it has been derived that the level of accuracy appears to be independent from the year of redaction of the executive design.

In case of single pier bents with wall-type section the median discrepancy affecting the estimation of longitudinal reinforcement ranges between an underestimation of $12 \%$ and an overestimation of $20 \%$, which can be considered a fairly good grade of accuracy. On the other hand, the average discrepancy affecting transversal reinforcement ranges between an underestimation of $20 \%$ and an overestimation of $120 \%$, which is extremely far from the assumed acceptability limit. On this issue, it should be recalled that the majority of the considered case studies seem to be in contrast with the contemporary regulations about the maximum allowable spacing of the transversal reinforcement bars.

The two considered cases of bridges with framed bents cannot be regarded to be part of the same category, because of incomparable bent heights which lead to very different level of accuracy. The bridge over the Adige river is characterised by piers with constant height of 5.3 
meters; the piers of the viaduct over the Rio Torto river have very different heights ranging from 13.8 to 41.35 meters. Nevertheless, it can be generally observed that the simulated design method achieve a fairly good grade of accuracy (overestimation not exceeding $30 \%$ ) for those part of the structure where the required reinforcement is determined by the magnitude of the applied actions (i.e. lower part of tall columns or beams), while less satisfactory results (underestimation up to 50\%) are achieved for the parts where the minimum prescribed reinforcement results to be adequate (i.e. upper parts of tall columns or short columns). This could be related to the fact that construction requirements or other design choices could have lead designers to adopt a higher quantity of reinforcement independently from contemporary prescriptions and from the level of design actions.

For what concerns the single pier bents with hollow rectangular or circular sections the longitudinal reinforcement results to be generally underestimated. The median discrepancy is $35 \%$, which exceeds the adopted acceptability limit. The discrepancy affecting the estimation of transversal reinforcement for this type of substructures also results not to be always satisfactory, with peaks of $33 \%$ overestimation and of $40 \%$ underestimation.

\section{SEISMIC RESPONSE ASSESSEMENT OF THE BRIDGES}

The simplified method for simulated design determines a discrepancy in the estimation of steel reinforcement of member sections. In order to investigate the influence of such discrepancy on the seismic response assessment of the whole structure, both nonlinear static and dynamic analyses have been performed. Each bridge has been analysed considering the outputs of the simulated design and the data derived from the executive design drawings. The results have been compared evaluating the discrepancy in terms of base shear, deck displacement and section hysteresis. The results of two structures among those considered for the validation of the simulated design method will be discussed in this Section: the viaduct "Egolo" in Caltagirone (Catania) and the bridge over the Rio Torto river in Castiglione dei Pepoli (Bologna). The analyses have been performed by means of the commercial software Midas Civil. The finite element model of each bridge is characterised by masses lumped in the joints and by fibre beam-column elements with distributed inelasticity able to catch the nonlinear response of the piers. The fibre beam element is a standard Euler-Bernoulli force-based beam element since, to the authors' knowledge, the axial-flexure-shear interaction is not yet implemented in a commercial software ([33] $\div[38])$. The Kent-Park constitutive model is adopted for modelling the behaviour of concrete, the Menegotto-Pinto constitutive relationship is used for steel.

Before analysing the bridges, a comprehensive review of the state-of-the-art and code provisions about nonlinear static analysis methods has been required in order to determine the most appropriate one for the above mentioned purpose. It should be recalled that nonlinear static analysis procedures have been developed for seismic assessment and design of regular buildings, whose seismic response is mainly dominated by the fundamental mode of vibration.

The basic conceptual procedure consists of the following steps:

- Estimation of the push-over curve by means of bi-dimensional incremental nonlinear analysis. The curve relates the total base shear $\mathrm{V}_{\mathrm{b}}$ to the lateral displacement $\mathrm{u}_{\mathrm{R}}$ of a reference degree of freedom (DOF), usually a node of the roof level is chosen in case of building analysis.

- Derivation of the equivalent SDOF system capacity curve from push-over curve; the former relates the applied lateral force $\mathrm{V}^{*}$ to the corresponding lateral displacement $\mathrm{D}^{*}$.

- Estimation of displacement demand of the SDOF system by means of either over damped or reduced elastic spectrum. 
- Derivation of seismic response parameters by means of the incremental nonlinear analysis database for the step corresponding to the SDOF target displacement.

Within the above described conceptual framework, several variations of this method have been proposed in order to improve its accuracy ([39]:[41]). Attempts have also been made by Chopra and Goel [42] and by Casarotti and Pinho [43] in order to take higher mode effects into account, despite the methods are based on equivalent SDOF systems for seismic demand estimation. The current state-of-the-art on nonlinear static method for bridge assessment is represented by the following commonly employed push-over-based methods: i) Capacity Spectrum Method (CSM), ii) N2 Method, iii) Modal Pushover Analysis (MPA) and iv) Adaptive Capacity Spectrum Method (ACSM). The application of these procedures to bridges required an ad-hoc selection of the reference joint, with the exception of the ACSM method.

According to the prescriptions of the Italian building code [44] and on the basis of the review of the state-of-the-art concerning non-linear static analysis of bridges, the modal pushover analysis (MPA) method and N2 method have been employed respectively for the transversal and longitudinal seismic response assessment of the continuous-deck bridge over the Rio Torto rived in Castiglione dei Pepoli. The latter method has also been employed for the transversal and longitudinal seismic response assessment of the Viaduct "Egolo" in Caltagirone.

The non-linear dynamic analysis consists in the direct integration of the system of equations of motion referred to the analysed structure. The forcing function is a ground acceleration time history, assigned at the base nodes of the finite element model. The implicit method of Newmark is adopted for the integration, performing Newton-Raphson iterations until convergence is obtained for each step increment of the considered ground acceleration time history. For the aims of this work, suites of natural accelerograms compatible with the considered elastic acceleration response spectrum for the collapse limit state, have been obtained by means of the software REXEL [45], which provides suites of 7 spectrumcompatible ground motions (each including up to three components) chosen within the European Strong Motion Database. In this work, single component ground motions have been selected within a limited group of events matching the magnitude and distance characteristics obtained through the de-aggregation of the uniform hazard spectrum. The elastic damping has been modelled by means of Rayleigh's approach with a percentage of $2 \%$ damping in correspondence of the first two periods of the structure (the fundamental period has been adopted for SDOF systems).

\subsection{Nonlinear static analysis of the bridge "Egolo"}

This RC bridge (Figure 3) consists of a 24-span discontinuous deck resting on single-pier bents of different heights. Since no translational constraint is provided between adjacent spans, each pier can be analyzed separately from the rest of the structure for what concerns both the transversal and longitudinal response, in agreement with the nonlinear static approach proposed in the Italian Building Code [44]. In order to investigate the influence of the discrepancy in member reinforcement due to the simulated design procedure, the response of two representative piers has been analyzed. The latter are the shortest $(7.3 \mathrm{~m})$ and the tallest $(14.7$ $\mathrm{m})$ pier of the bridge and they have hollow circular cross-section (Figure 3). The seismic hazard of the site where the bridge is located has been determined according to the Italian Building Code[44]. The seismic hazard parameters have been inferred from the Italian hazard map in correspondence of the geographical coordinates of the bridge. Two limit states are considered in the analysis - SLC and SLV according to D.M. 2008 [44]. 


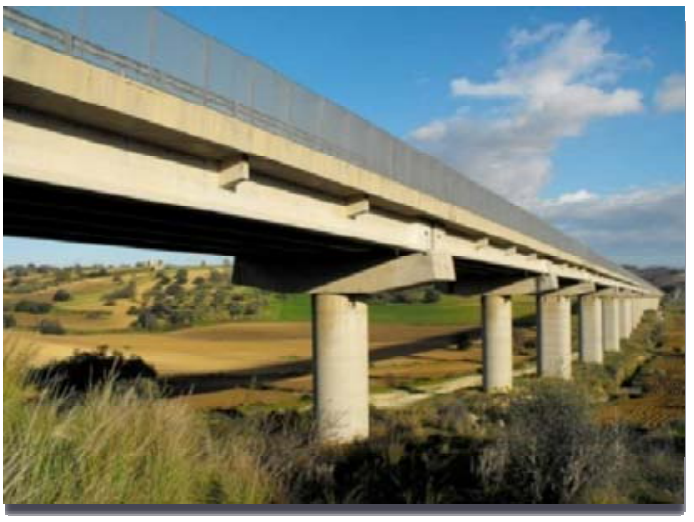

(a)
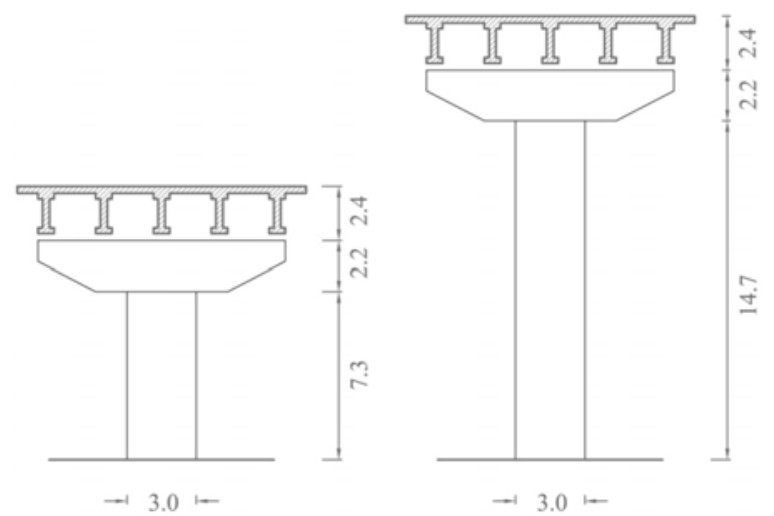

(b)

Figure 3: Viaduct "Egolo" (Caltagirone, 1988): general view (a) and its shortest and tallest piers (b)

Each pier is considered as a SDOF system with a mass M lumped at the deck centre of mass. The mass $M$ has been assumed to include the mass of the tributary deck length, that of the cap beam and $1 / 3$ of that of the pier. A force-based and displacement controlled pushover analysis has been performed for each pier.

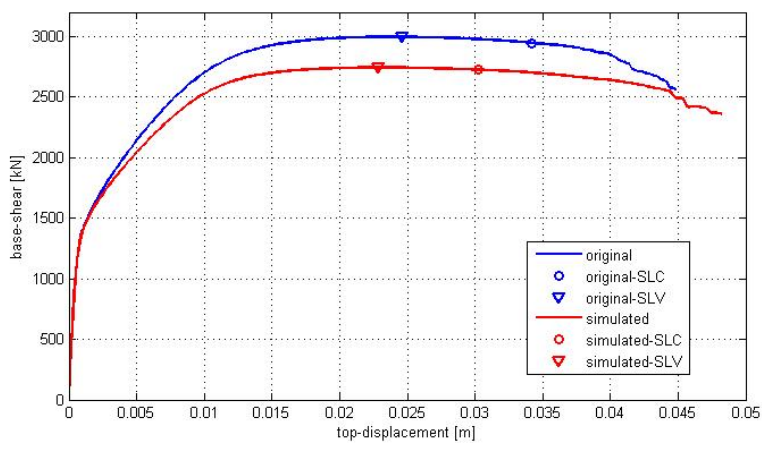

(a)

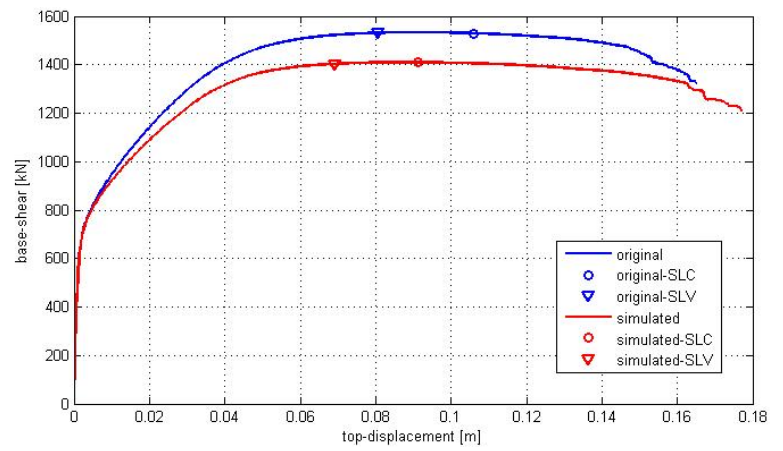

(b)

Figure 4: Pushover curves and performance points for the damage and collapse limit states for the shortest (a) and the tallest pier (b)

\begin{tabular}{llll}
\hline Pier & & $\mathrm{V}_{\mathrm{SLC}}(\mathrm{kN})$ & $\mathrm{V}_{\mathrm{SLV}}(\mathrm{kN})$ \\
\hline Smallest pier & Executive drawings & 2947 & 2995 \\
& Simulated design & 2725 & 2743 \\
\multirow{4}{*}{ Tallest pier } & Difference (\%) & -7.5 & -8.4 \\
& Executive drawings & 1530 & 1530 \\
& Simulated design & 1410 & 1403 \\
& Difference (\%) & -7.8 & -8.3 \\
\hline
\end{tabular}

Table 1: Influence of the reinforcement discrepancy on the base shear considering two limit states (where SLC and SLV are two limit states defined as in D.M. 2008 [44]

As result of the simulated design, an underestimation of longitudinal reinforcement of about $15 \%$ was obtained. Such discrepancy directly affects the pushover curve of both piers, as shown in Figure 4. The base-shear capacity results to be underestimated of about $10 \%$ and $7 \%$ for shortest and tallest pier, respectively. Anyway the assessment of the general behaviour of the piers is not affected by the reinforcement discrepancy. A lower maximum capacity of the system implies a higher elastic stiffness, provided that the elastic branch of the curve is coincident. This overestimation of the ideal elastic stiffness produces an underestimation of 
about $15 \%$ in the estimation of the displacement demand (i.e. performance point) for both the considered piers.

The reinforcing discrepancy results to have a very low influence on the estimation of the base shear and bending moment demands, which is slightly (below 10\%) underestimated for both the considered piers, as reported in Table 1. Nevertheless, it should be noticed that the seismic demand for the bridge location is not adequate to bring the piers widely into the inelastic branch of the response, as can be observed in Figure 4.

\subsection{Nonlinear dynamic analysis of the bridge "Egolo"}

In order to further investigate the influence of the discrepancy in member reinforcement on the seismic response, nonlinear dynamic analysis has been performed for the above mentioned representative piers of the bridge. Since the piers have a circular section and are analyzed separately from the rest of the bridge, there is no difference in transversal and longitudinal response. Therefore, the selected ground motions have been arbitrarily applied in transversal direction. The analysis employs the same distributed plasticity FE model of the nonlinear static analysis. The results of the analyses of the bridge with the reinforcement derived from the simulated design are compared with the results of the bridge with reinforcement obtained from the executive drawings. The deck displacements (i.e. the displacement of the top of the pier) and the base shear of the piers have been compared (Table 2).

The influence of member reinforcement discrepancy on top-displacement response is quite significant for the shortest pier. The FE model with simulated design reinforcement, which is affected by a $15 \%$ underestimation, generally experiences a higher top-displacement than the one with the original reinforcement (Table 2). On the other hand, the top-displacement of the tallest pier does not appear to be significantly affected by the discrepancy of reinforcement. This could be due to its higher deformation capacity within the elastic range.

The base shear response is not significantly affected by the discrepancy in member reinforcement and is generally affected by an underestimation of about $10 \%$ (Table 2). This is consistent with the $15 \%$ underestimation of the longitudinal reinforcement obtained from the simulated design procedure.

It can be concluded that the discrepancy in the estimation of the member reinforcement has a small influence on the assessment of the seismic response of the considered piers, in particular when the tallest and more flexible pier are considered.

\begin{tabular}{lllll}
\hline Pier & \multicolumn{2}{l}{ Maximum deck displacement } & \multicolumn{2}{l}{ Maximum base shear } \\
\hline & Average & Average & Average & Average \\
& difference $(+)[\%]$ & difference $(-)[\%]$ & difference $(+)[\%]$ & difference (-) [\%] \\
Smallest pier & +6.5 & +39.2 & -10.5 & -4.3 \\
Tallest pier & -10.0 & -7.7 & -10.0 & -7.7 \\
\hline
\end{tabular}

Table 2: Influence of simulated design on the maximum deck displacement and the maximum base shear

\subsection{Nonlinear static analysis of the bridge over the Rio Torto river}

Since the bridge presents a continuous deck, it is not possible to analyze each bent as if it was an independent single degree of freedom (SDOF). Nevertheless, the dilatation gaps located between the spans are assumed not to transmit transversal actions between one deck segment to the other. This allows the transversal seismic response of each segment to be analyzed separately from the rest of the structure. Moreover, since the deck consists of two independent girders, the structure can be simplified as if it consisted of two identical bridges next to each other and analyzed separately. The analyses presented herein are limited to the transversal and longitudinal response of the portion of the bridge shown in Figure 5. 


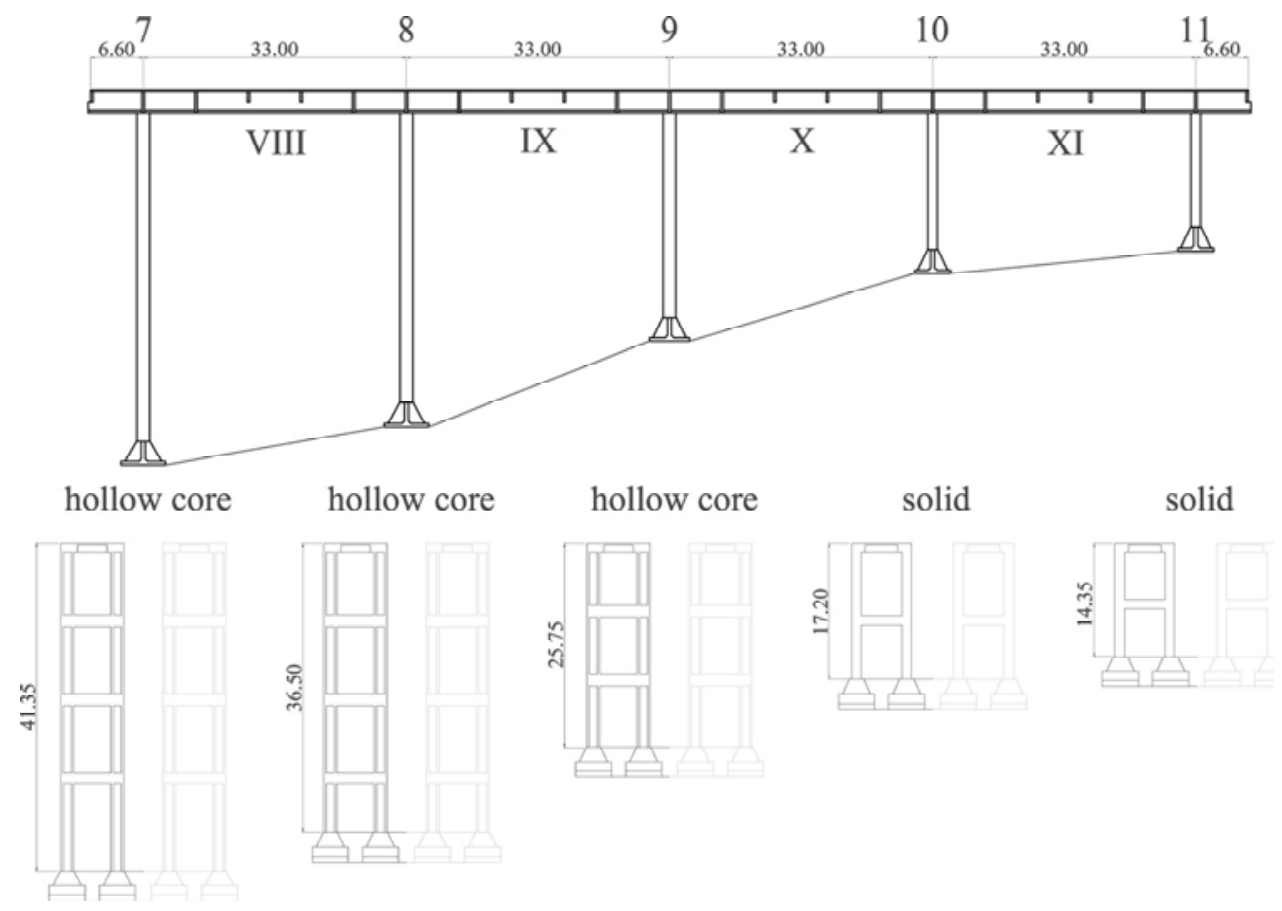

Figure 5: Analysed portion of the viaduct over the Rio Torto river (1950, Roncobilaccio)

The numerical model consists of a lumped-mass and distributed plasticity model and employs mono-dimensional frame elements both for the bridge deck and the bent columns and beams (Figure 6) . Each span of the bridge deck has been divided in three elastic elements of $11 \mathrm{~m}$ each; the two cantilever portions of the deck are not included in the model, but the corresponding mass is lumped at the deck end joints. The former elements are located at a distance from the cap-beam axis consistent with the position of the centre of mass of the deck section and are assigned a generic sectional shape with the same geometrical properties of the actual deck section. The connection between deck elements and the bents is such that all the translational displacements are constrained and that the torsion and the transversal bending of the deck are transmitted to the bents by means of vertical and horizontal forces, respectively. This is achieved by means of two additional joints, with the spatial coordinates equal to the nodes of the top of the columns, constraint to behave as a rigid body with the deck centre of mass in all directions except from the transversal one. Those nodes are hinged to the column top nodes by means of spring elements with high translational stiffness and negligible rotational stiffness. The afore described ideal connection is sketched in Figure 6, where $\mathrm{K}[\mathrm{kN} / \mathrm{m}]$ and $\mathrm{Kr}[\mathrm{kNm} / \mathrm{rad}]$ stand respectively for the axial and flexural stiffness, while $\mathrm{D}$ and $\mathrm{R}$ stand respectively for translational and rotational degrees of freedom (1 standing for constrained DOF). No restrains are applied to the deck end nodes, due to the presence of the dilatation gaps.

As mentioned before, the selected method for the non-linear static analysis is the Modal Pushover Method (MPA), since it represents a satisfactory trade-off between computational simplicity and analytical accuracy and is also recommended by the current Italian Building Code [44] for seismic assessment of existing bridges with continuous deck.

In order to proceed with the modal pushover analysis, the significant modes of vibration for the transversal seismic response of the bridge have been identified by means of modal analysis. The deck mass has been lumped at the elements nodes. The actual distribution of mass within the bents has been considered by means of the consistent mass approach. The uncracked gross section of the members has been considered for the analysis, since a reduction 
of member stiffness would only affect the estimation of modal forces, which have no relevance within the MPA approach. Stiffness reduction is expected to have a negligible effect on the modal shapes and participant mass factors, which are of primary importance for MPA.
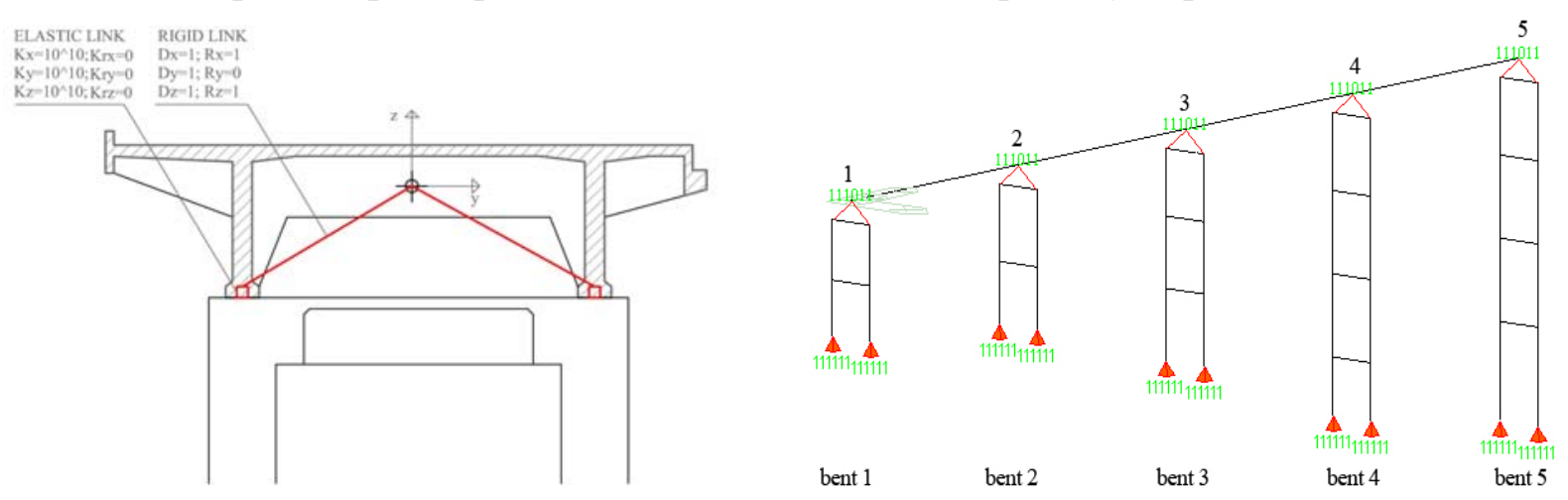

Figure 6: FE model of the analysed portion of the viaduct over the Rio Torto river

The first two transversal modes of vibration sum up a participant mass of $87.3 \%$ and, thus, have been considered to be adequate for the assessment of the transversal seismic response of the bridge through MPA. The modal parameters of interest within the presented analysis procedure are M.P.M. which stands for the modal participant mass and $\Gamma$ which stands for the modal participation factor. The results of the modal analysis are not affected by the discrepancy in steel reinforcement evaluation highlighted, since the reinforcement configuration and quantity are not involved.

Two non-adaptive force-based and displacement-controlled push-over analysis have been carried out, one for each of the above mentioned mode of vibration. The load pattern for each analysis have been defined according to modal shapes. The node expected to experience the maximum lateral displacement has been chosen as reference point for the pushover curve.

Since the structure is symmetric with respect to its longitudinal axis, the transversal response is not changing with the sign of the loading pattern (i.e. positive or negative direction). Therefore, only the positive direction has been adopted for the analysis. It should be also pointed out that geometrical non-linearity is not taken into account since this kind of analysis is not supported by the software Midas Civil in combination with the distributed plasticity approach. The procedure has been repeated for two different models, one being assigned the reinforcement configuration and quantity reported in the available executive drawings and the other being assigned the reinforcement configuration and quantity estimated by means of the simulated design procedure. A total of four push-over curves is obtained for the bridge.

The discrepancy in member reinforcement has a limited impact on the transversal pushover curves for both the load patterns. A first observation is that the load pattern (a) proportional to mode 2 results in a far more flexible response of the bridge than load pattern (b) proportional to mode 3. The elastic stiffness is much lower for pattern (a) with respect to pattern (b). This is due to the fact that the former is much more demanding for the flexible side of the sub-structure (i.e. bents 3-4-5), which is able to experience larger elastic deformations, than for the stiff side (i.e. bents 1-2). The latter, instead, allocates the forces more uniformly along the deck and particularly involves the stiff side of the substructure.

Moreover, the bridge displays a higher shear capacity and a hardening behaviour for pattern (a) and a softening behaviour for pattern (b). Also this difference is related to the distribution of forces between the flexible and stiff side of the substructure. Due to limited elastic flexibility of bents 1 and 2, plastic hinges are rapidly developed at column base sections for pattern (b) and manifest a relatively brittle behaviour because of low confinement and severe 
compressive loading. The aforementioned observations on the structure behaviour are confirmed by the comparison of the individual push-over curves for each bent and each load pattern. Bents 1-2 experience very low displacement levels with respect to bents 4-5 for pattern (a), while the opposite can be observed for pattern (b). Combining this with the fact that the curvature demand at column base section is sensibly lower for flexible bents 3-4-5, a further explanation of the different behaviour of the structure for load pattern (a) and (b) is provided. The influence of the member reinforcement discrepancy, due to simulated design, on the pushover curves is observed to be fairly low and not to affect the global behaviour of the structure. Nevertheless, a noticeable influence can be observed on the base-shear capacity of the bridge for both load patterns (a) and (b), which results to be lower for the model with simulated reinforcement. For what concerns pattern (a), it should be noted that in the model with simulated reinforcement the flexural capacity of column members of bents 3-4-5, which practically govern the response, is overestimated at the base sections and underestimated at the intermediate sections. This is consistent with the results of simulated design, which provide a $12 \%$ overestimation and a $50 \%$ underestimation of longitudinal reinforcement for base and top sections, respectively. The combination of the two aforementioned opposite effects leads to a slight underestimation of the base-shear capacity, specially for high displacement levels at which the concrete cracking interests also the upper part of the columns and allow the reinforcement underestimation to affect the capacity. On the other hand, the base shear capacity for low displacement levels appears not to be affected by the reinforcement underestimation at the upper part of the columns, where concrete cracking has not yet occurred, and therefore results to be slightly overestimated, consistently with the overestimation of reinforcement at column base-sections obtained in simulated design.

For what concerns pattern (b), it should be noted that, in the model with simulated reinforcement, the flexural capacity of column members of bents 1-2, which practically governs the response, is underestimated at the base sections. This can be related to an even more brittle behaviour of the section with simulated design reinforcement with respect to the original one, due to a longitudinal reinforcement overestimation of $28 \%$. The effect of such reinforcement discrepancy directly reflects on the response of the whole bents $1-2$, since no cracking of the sections is achieved at the upper part of the columns.

In order to investigate the influence of reinforcement discrepancy on the assessment of the transversal seismic response of the structure the performance point has been computed for each load pattern and the corresponding response parameters (deck-displacement and base shear) have been combined according to SRSS rule. The determination of the performance point, i.e. the seismic demand on the structure, associated to each of the two load patterns require each pushover curve to be transformed in the idealized capacity curve $V_{n}{ }^{*}-D_{n}{ }^{*}$ of the corresponding equivalent SDOF system.

As it can be observed in Figure 7, there is a significant difference for the elastic stiffness of the equivalent SDOF systems for both modal push-over cases. In particular, the load pattern (a) results in an overestimation of $17 \%$, which is consistent with the aforementioned observations related to the structural response. On this subject, it should also be noted that the elastic stiffness estimation by means of the code based approach is affected by the discrepancy in the maximum base-shear capacity; in fact, a lower maximum capacity of the system implies a higher stiffness, provided that the elastic branch of the curve is coincident. The load pattern (b) results in an elastic stiffness overestimation of about $9 \%$, which is only due to the difference in the maximum base-shear capacity of the system. The error in the estimation of the elastic stiffness of the equivalent SDOF system results in a low discrepancy in the estimation of the displacement demand for both the modal pushover cases. Therefore, there is no significant influence on the computation of the performance point for both cases, as shown in Figure 8. 

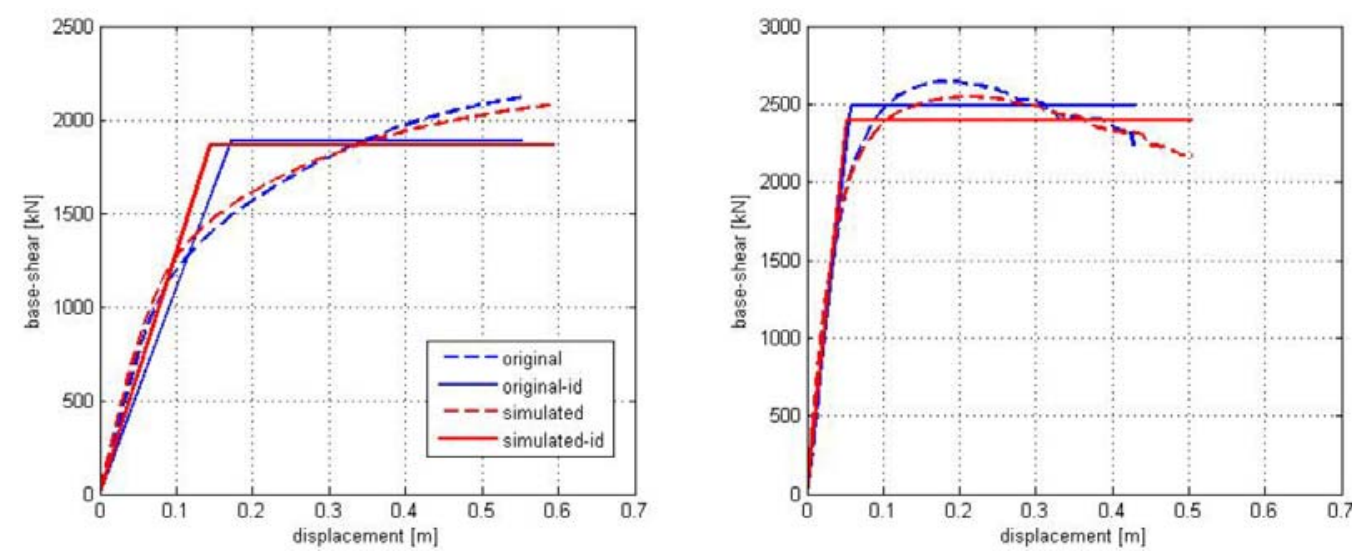

Figure 7: MPA - Capacity curves of the equivalent SDOF systems for mode 2 (left) and mode 3 (right)

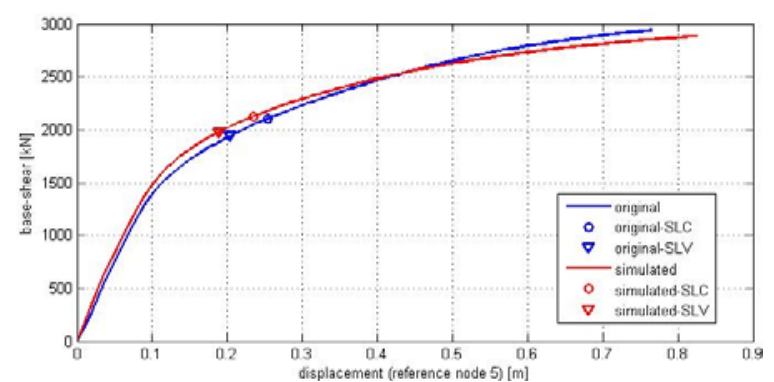

(a)

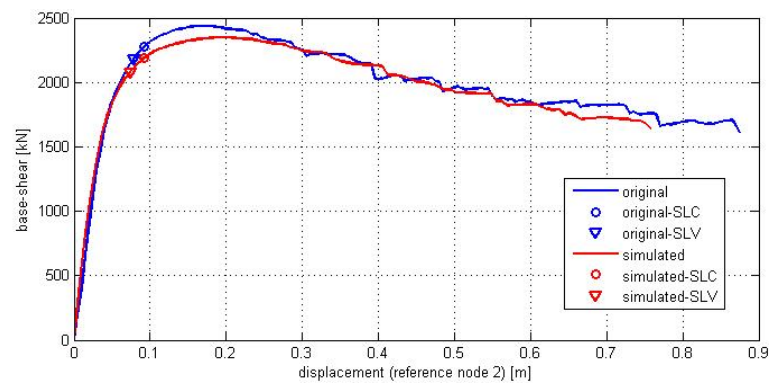

(b)

Figure 8: MPA - Performance points for SLC and SLV limit states for load patterns (a) and (b)

For what concerns the assessment of the transversal response of the bridge it can be concluded that the influence of the discrepancy in steel reinforcement is negligible. The difference in the estimation of the deck-displacement for SLC limit state is well below the $10 \%$ (Table 3), the response of the structure being generally underestimated due to the overestimation of elastic stiffness. The difference in the estimation of the base shear at each bent for the same limit state is well below the $5 \%$ (Table 3 ), the action being slightly underestimated and overestimated respectively for the stiff side and the flexible side of the substructure.

\begin{tabular}{lllllll}
\hline Node & & 1 & 2 & 3 & 4 & 5 \\
\hline Deck displacement [cm] & Executive drawings & 11.2 & 8.7 & 9.1 & 15.2 & 24.5 \\
& Simulated design & 11.0 & 8.4 & 8.5 & 14.5 & 23.8 \\
& Difference (\%) & -1.8 & -3.5 & -6.6 & -4.6 & -2.9 \\
\hline Bent & & 1 & 2 & 3 & 4 & 5 \\
\hline Base shear [kN] & Executive drawings & 1075 & 853 & 1130 & 732 & 742 \\
& Simulated design & 1040 & 840 & 1145 & 753 & 754 \\
& Difference (\%) & -3.3 & -1.5 & +1.3 & +2.9 & +1.6 \\
\hline
\end{tabular}

Table 3: MPA - Influence of reinforcement discrepancy on bridge deformed shape and base-shear for SLC limit state

It can be concluded that the discrepancy in steel reinforcement estimation of members has a low influence on the assessment of the transversal bridge response, but it should also be pointed out that the level of seismic demand is relatively low. A more sever seismic hazard would eventually have resulted in a more relevant influence because of a larger excursion in the nonlinear branch of the response. The former is no doubt more affected by the discrepancy, in particular for the load pattern (b) proportional to mode 3. 
In order to investigate the influence of the reinforcement discrepancy on the assessment of the longitudinal response of the bridge a non-adaptive force-based and displacement controlled pushover has been performed. According to the Italian Building Code approach for continuous deck bridges, the structure has been considered as a SDOF system and the displacement at the deck level has been adopted for the push-over analysis. Since the longitudinal response is not changing with the sign of the loading pattern (i.e. positive or negative direction), only the positive direction has been adopted for the analysis. The procedure has been repeated for two different models, one being assigned the reinforcement configuration and quantity reported in the available executive drawings and the other being assigned the reinforcement configuration and quantity estimated by means of the simulated design procedure. A total of two push-over curves is obtained for the bridge.

As shown on the left of Figure 9, the discrepancy in member reinforcement has a limited impact on the longitudinal pushover curve for what concerns the maximum base shear capacity and the global behaviour of the structure within the elastic and yielding branch of the response. On the other hand, the global behaviour of the structure is significantly affected for what concerns the inelastic branch, where the original structure suffers a more severe softening than the one with simulated design reinforcement. This is due to the influence of the reinforcement discrepancy on the column sectional response, which generate a difference in the softening branch of the response in the columns of bents 1-2 and a slightly higher postyielding flexural capacity in the columns of bents 3-4-5.

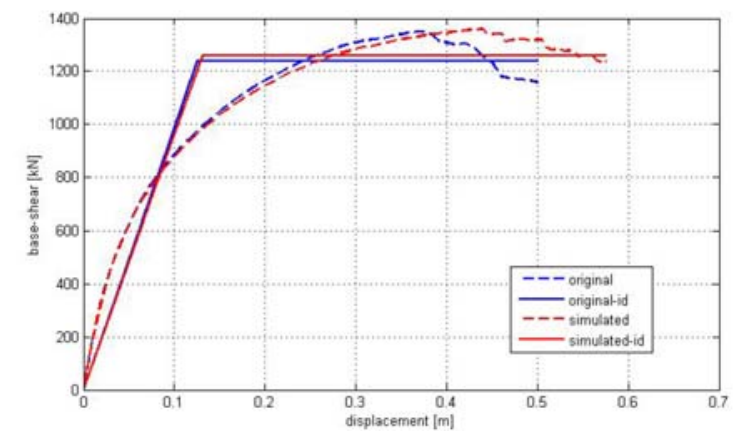

(a)

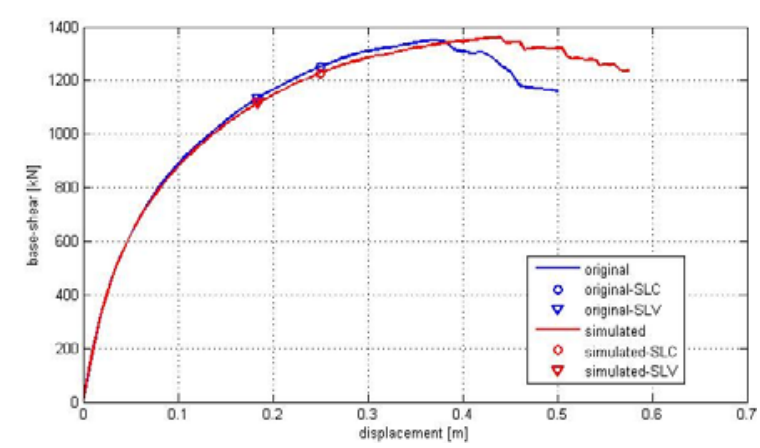

(b)

Figure 9: Capacity curve of the SDOF system - longitudinal direction (a). Performance points for SLC and SLV limit states (b)

The local behaviour of the members seems to be more significantly affected by the reinforcement discrepancy in longitudinal direction than it is in transversal one, in particular for taller hollow core columns. In the original structure, the nonlinearity is concentrated at the base of the columns, since their longitudinal reinforcement is almost constant along the height. In the structure with simulated design reinforcement, on the other hand, the nonlinearity is not concentrated at the base of the columns, which are affected by an overestimation of $12 \%$ and an underestimation of $50 \%$ for the longitudinal reinforcement of the bottom and top parts, respectively. This effect is particularly evident for the columns of bent $n^{\circ} 3$, which is subjected to a higher level of moment due to its higher stiffness with respect to the other two hollow core bents.

In order to investigate the influence of reinforcement discrepancy on the assessment of the longitudinal seismic response of the structure the performance point has been computed according and the corresponding response parameters (deck-displacement and base-shear) have been derived from pushover analysis. As shown on the right of Figure 9, there is no influence of reinforcement discrepancy on the estimation of the displacement demand for SLC and SLV limit state, since the equivalent period $\mathrm{T}^{*}$ corresponds to the displacement plateau for both 
models. The difference in the estimation of the base shear at each bent for the SLC limit state is well below the $5 \%$, the action being slightly underestimated and overestimated respectively for the stiff side and the flexible side of the substructure.

It can be concluded that the discrepancy in the estimation of member steel reinforcement has a low influence on the assessment of the longitudinal bridge response, at least for seismic requirements in Italy, where there is a low probability of large non-linear excursions of the piers.

\subsection{Nonlinear dynamic analysis of the bridge over the Rio Torto river}

The nonlinear analysis is focused on the portion of the bridge shown in Figure 5. Each considered acceleration time history has been applied independently in transversal and longitudinal direction. This simplification is considered to be adequate for the purpose of this research work. Moreover, the decoupling of the two orthogonal responses seems to be consistent with the geometry of the bridge, which consists of a straight deck supported on a symmetric substructure with respect to the longitudinal axis. The analysis employs the same distributed plasticity FE model as the non linear static one.

The comparison between the transversal response of the original structure and the simulated one to each considered time history is carried out in terms of the displacement envelope of the deck. It can be stated that, in general, the simulated structure experiences sensibly lower displacements in the stiffer side of the substructure (i.e. bents 1-2) and slightly higher displacement of the more flexible side of the substructure (i.e. bents 4-5). This seems to be consistent with the difference in member reinforcement between the executive drawings and the simulated design, where a sensible overestimation of longitudinal and transversal reinforcements affects the columns of the stiffer side. However, the effect of the estimation in member reinforcement seems to have a low influence on the displacement response, with an average percent difference in the displacement profile not exceeding $12.5 \%$.

The same can be concluded considering the base shear envelope, for which the influence of reinforcement discrepancy does not exceed the $11.5 \%$. The action results to be slightly overestimated for the bents at the end-segments of the bridge and underestimated for the others.

The influence of reinforcement discrepancy on the interstory drift of the bents results to be quite significant for the shorter ones (1-2) and almost negligible for the taller ones (3-4-5), as reported in Table 4. This could be related to the fact that the shorter and stiffer bents suffer more relevant excursions in the inelastic branch of sectional response and therefore their deformation is more affected by the reinforcement discrepancy than the taller ones. As expected, some variability of the influence is registered among the different accelerograms, related to their different frequency contents. However, it should be noted that the influence of the reinforcement discrepancy does not exceed $10 \%$ and $25 \%$ for tall and short bents, respectively.

The aforementioned average percent differences concerning the considered response parameters (i.e. deck displacement envelope, base shear envelope and interstory drift) can be regarded as an acceptable grade of accuracy in the assessment of the bridge seismic response. Nevertheless, it is important to point out that the response of the bent members remains almost entirely within the elastic field for the considered level of seismic actions and that the influence would have been more relevant for a higher seismicity level.

The influence of the discrepancy in steel reinforcement on the analysis of the longitudinal response is evaluated in terms of deck displacement and base shear. From the comparison of the results, it can be stated that the longitudinal response is no significantly affected by the discrepancy in member reinforcement estimation. This is due to the fact that the piers do not experience any significant excursion into the inelastic branch of their response. Therefore, the 
discrepancy in reinforcement amount does not play any significant role in the assessment of the bridge response in longitudinal direction.

\begin{tabular}{lllllll}
\hline Bent & & 1 & 2 & 3 & 4 & 5 \\
\hline Segment 1 & Difference (+) [\%] & -22.9 & -11.7 & -10.0 & -5.3 & +0.5 \\
& Difference (-) [\%] & -25.6 & -9.4 & -8.9 & -0.6 & +0.5 \\
Segment 2 & Difference (+) [\%] & 4.1 & -6.9 & -5.9 & -0.6 & +6.0 \\
& Difference (-) [\%] & 14.3 & -4.9 & -5.2 & +4.6 & +6.0 \\
Segment 3 & Difference (+) [\%] & - & - & -4.8 & -0.3 & +6.5 \\
& Difference (-) [\%] & - & - & -3.7 & +5.8 & +7.1 \\
Segment 4 & Difference (+) [\%] & - & - & - & -0.6 & +5.6 \\
& Difference (-) [\%] & - & - & - & +4.2 & +6.1 \\
\hline
\end{tabular}

Table 4: THA - Influence of simulated design on the interstory drift - average of the considered accelerograms

A scarcely appreciable influence of the reinforcement discrepancy is obtained in the estimation of base shear envelope for the shorter bents (1-2), which suffer higher excursions into the inelastic branch of sectional response than the taller ones (3-4-5). Anyway, the influence is well below the $5 \%$, and it can be concluded that no influence affects the response assessment.

\section{CONCLUSIONS}

The present work aimed to provide a simple procedure for simulated design of longitudinal and transversal reinforcement of existing RC bridge bents. The simulated design is a helpful tool within the seismic response assessment of existing structures whose reinforcement configuration is not available or in those cases when a large scale vulnerability assessment has to be performed on a large number of homogeneous structures. According to the obtained results, it can be concluded that the simulated design procedure is suitable to the seismic response assessment of existing RC bridges, when no detailed information is available on member reinforcement, since it does not significantly affect the results. Nevertheless, the proposed procedure could be further elaborated and developed in order to obtain an estimation of reinforcement detailing closer to the real structure subjected to seismic assessment.

First of all, a review of a wider set of original executive design documentation would allow to include in the procedure eventual tendencies in the practice of design and construction which are not inferable from the review of the contemporary design regulations. The same can be said for what concerns the choice of bar diameter and concrete cover. Moreover, such review could provide a wider documentation about the tendency in the choice of concrete and steel types for bridge bents, together with their mechanical properties; this would improve the correspondence of the input data to the contemporary technologies.

Secondly, limit states verifications such as cover concrete cracking and steel reinforcement fatigue could be included in the procedure in addition to allowable stress verifications, in order to take into account the possibility of more demanding conditions on reinforcement detailing.

Finally, the procedure could be elaborated in order to include a wider range of sectional geometries and bent typologies in order to obtain a more general methodology and avoid several simplifications which could affect its accuracy. This is the case of walls with smoothed extremities or hollow core elliptical piers, which are simplified as solid rectangular and hollow core rectangular section in the current procedure. This is also the case of tapered members and irregular framed bents, which are simplified respectively as non-tapered members 
with the average dimension expanded throughout the entire member length and as regular frames with constant inter-axis of bays and constant height of columns within the same level.

Further investigation could address the influence of the reinforcement discrepancy, due to simulated design, on the verification of local behaviour in terms of usage ratio of the chord rotation capacity and shear capacity of the bent members. The chord rotation capacity calculation according to the Italian Building Code [44] depends both on the reinforcement configuration and the seismic demand (in terms of bending moment distribution along the element) and, therefore, the evaluation of the influence of reinforcement discrepancy on this response parameter could be of interest. The same can be said for the shear capacity usage ratio, which is strongly affected by the reinforcement configuration and could be more sensitive to the discrepancy due to simulated design than the shear demand on the member itself.

\section{ACKNOWLEDGMENTS}

Thanks are given to the "Provincia Autonoma of Trento" and Dr Daniele Zonta (University of Trento) as well as the company ANAS s.p.a., for having kindly provided the executive design documentation about many of the bridges analysed in this work. The authors would like to thank Prof. Paolo Pinto and Dr Alessio Lupoi (University of Rome "La Sapienza"), who kindly provided the graphical documentation about the bridge over the River Rio Torto.

Thanks are given to Dr Barbara Borzi (Eucentre) for her supervision during the development of the Master thesis of the second author, and to Dr Ricardo Monteiro (IUSS) for the fruitful discussion about FE modeling of bridges. The authors are grateful to Ms Lucia Cecere (Library of "Ministero delle Infrastrutture e dei Trasporti") and to Ms Roberta Lucentini (formerly, Documentation Centre of Eucentre) for their effective assistance in the collection of the contemporary design regulatory framework.

\section{REFERENCES}

[1] B. Borzi, P. Ceresa, M. Faravelli, E. Fiorini, M. Onida, Seismic Risk Assessment of Italian School Buildings. Computational methods in applied sciences, 30, 317-344, 2013.

[2] B. Borzi, P. Ceresa, P. Franchin, F. Noto, G.M. Calvi, P.E. Pinto, Seismic Vulnerability of the Italian Roadway Bridge Stock, Earthquake Spectra, 31(4), 2137-2161, 2015.

[3] G. Albenga, I Ponti. L'esperienza, U.T.E.T., Torino, Italy 1985a.

[4] G. Albenga, I Ponti. La teoria, U.T.E.T., Torino, Italy, 1985 b.

[5] G. Albenga, I Ponti. La pratica, U.T.E.T., Torino, Italy, 1985 c.

[6] M. Greco, Costruzioni di ponti, lezioni di, Arti Grafiche Castiglia, Palermo, Italy, 1928.

[7] A.F. Jorini, Costruzione dei ponti - Teoria e pratica, Hoepli, Milano, Italy, 1927.

[8] A. Raithel, Costruzioni di ponti, Liguori, Napoli, Italy, 1964.

[9] A. Raithel, Costruzioni di ponti, Liguori, Napoli, Italy, 1970.

[10] A. Raithel, Costruzioni di ponti, Liguori, Napoli, Italy, 1977.

[11] L. Santarella, Ponti in muratura ed in cemento armato, Edizioni del gruppo universitario fascista, Milano, Italy, 1930. 
[12] L. Stabilini, Ponti, Libreria Editrice Tecnica Cesare Tamburini, Milano, Italy, 1954.

[13] Circolare n.7100, Carichi da considerare nella progettazione delle strade militari, Ministero della Guerra, (11 aprile) 1930.

[14] Normale n.8, Carichi da considerare nel calcolo dei ponti per strade ordinarie, Ministero dei Lavori Pubblici, G.U. 21/10/1933 n.30, 1933.

[15] Normale n.1, Carichi da considerare nel calcolo dei ponti per strade ordinarie, Ministero dei Lavori Pubblici, (9 giugno) 1945.

[16] Circolare n.820, Carichi per la progettazione delle strade, Ispettorato Tecnico A.N.A.S., (15 marzo) 1952.

[17] Circolare n.384, Norme relative ai carichi per il calcolo dei ponti stradali, Ministero dei Lavori Pubblici, (14 febbraio) 1962.

[18] D.M. 1980a, Norme tecniche per la disciplina di opere in cemento armato normale e precompresso ed a struttura metallica, G.U.R.I. 28/6/1980 n.176, 1980a.

[19] D.M. 1980b, Criteri generali e prescrizioni tecniche per la progettazione, esecuzione e collaudo dei ponti stradali, G.U.R.I. 10/11/1980 n.308, 1980b.

[20] R.D.L. n.2105, Norme tecniche di edilizia per tutti i comuni del Regno e speciali norme tecniche di edilizia asismica per i paesi colpiti da terremoti, G.U. 27/12/1937 n.298, 1937.

[21] L. n.1684, Norme tecniche di edilizia con particolari prescrizioni per le località colpite dai terremoti, G.U.R.I. 22/12/1962 n.326, 1962.

[22] L. n.64, Provvedimenti per le costruzioni con particolari prescrizioni per le zone sismiche, G.U.R.I. 21/3/1974 n.76, 1974.

[23] R.D. n.2229, Norme per la esecuzione delle opere in conglomerato cementizio semplice od armato, G.U. 18/4/1940 n.92, 1939.

[24] Circolare n.1472, Le armature delle strutture in cemento armato, Ministero dei Lavori Pubblici, (23 maggio) 1957.

[25] Circolare n.1547, Caratteristiche e modalità di impiego nel cemento armato degli acciai ad aderenza migliorata, Ministero dei Lavori Pubblici, (17 maggio) 1965.

[26] L. n.1086, Norme tecniche per la disciplina di opere in cemento armato normale e precompresso ed a struttura metallica, G.U.R.I. 21/12/1971 n.321, 1971.

[27] L. Marziali, Seismic response assessment of RC bridges, Master Dissertation, UME Graduate School (ROSE Programme), IUSS Pavia, 2011.

[28] E. Fagà, P. Ceresa, R. Nascimbene, M. Moratti, A. Pavese, Modelling curved surface sliding bearings with bilinear constitutive law: effects on the response of seismically isolated buildings, Materials and Structures, 49(6), 2179-2196, 2016.

[29] G.M. Verderame, G. Manfredi, G. Frunzio, Le proprietà meccaniche dei calcestruzzi impiegati nelle strutture in cemento armato degli anni '60, 10th ANIDIS National Conference on Earthquake Engineering in Italy, Potenza-Matera, Italy, 2001a.

[30] G.M. Verderame, A. Stella, E. Cosenza, Le proprietà meccaniche degli acciai impiegati nelle strutture in cemento armato degli anni '60, 10th ANIDIS National Conference on Earthquake Engineering in Italy, Potenza-Matera, Italy, $2001 \mathrm{~b}$. 
[31] D.M. 1972, Norme tecniche per la disciplina di opere in cemento armato normale e precompresso ed a struttura metallica, G.U.R.I. 22/7/1972 n.190, 1972.

[32] D.M. 1974, Norme tecniche per la disciplina di opere in cemento armato normale e precompresso ed a struttura metallica, G.U.R.I. 29/7/1974 n.198, 1974.

[33] P. Ceresa, L. Petrini, R. Pinho, Flexure-Shear Fiber Beam-Column Elements for Modeling Frame Structures Under Seismic Loading — State of the Art. Journal of Earthquake Engineering, 11(1), 46-88, 2007.

[34] P. Ceresa, L. Petrini, R. Pinho, R. Sousa, A fibre flexure-shear model for seismic analysis of RC-framed structures. Earthquake Engineering and Structural Dynamics, 38, 565-586, 2009.

[35] A. Kagermanov, P. Ceresa, Physically-based cyclic tensile model for RC membrane elements. Journal of Structural Engineering ASCE, 142(12) DOI:10.1061/(ASCE)ST.1943541X.0001590, 04016118, 2016.

[36] A. Kagermanov, P. Ceresa, Fiber-section model with an exact shear strain profile for two-dimensional RC frame structures. Journal of Structural Engineering ASCE (in press).

[37] P. Ceresa P, A. González Víquez, Nonlinear analysis of shear critical RC members using current FE software, 6th ECCOMAS Thematic Conference, Computational Methods in Structural Dynamics and Earthquake Engineering, COMPDYN 2017, 15-17 June, 2017.

[38] P. Ceresa, G. Negrisoli, Hysteretic models considering axial-shear-flexure interaction, Procedia Engineering, World Multidisciplinary Civil-Engineering-Architecture-Urban Planning Symposium - WMCUAS, Prague, 12-16 June, 2017.

[39] S.A. Freeman, J.P. Nicoletti, J.V. Tyrell, Evaluation of existing buildings for seismic risk - A case study of Puget Sound Naval Shipyard, Bremerton, Washington, U.S. National Conference on Earthquake Engineering, Berkeley, California, 1975.

[40] S.A. Freeman, Development and use of capacity spectrum method, $6^{\text {th }}$ U.S. National Conference on Earthquake Engineering, Seattle, Washington, 1998.

[41] P. Fajfar, P. Gašperšič, The N2 method for the seismic damage analysis of RC buildings, Earthquake Engineering and Structural Dynamics, 25, 31-46, 1996.

[42] A.K. Chopra, R.K. Goel, A modal pushover analysis procedure for estimating seismic demands for buildings, Earthquake Engineering and Structural Dynamics, 31, 561-582, 2002.

[43] C. Casarotti, R. Pinho, An Adaptive Capacity Spectrum Method for assessment of bridges subjected to earthquake action, Bulletin of Earthquake Engineering, 5, 377-390, 2007.

[44] D.M. 2008, Norme tecniche per le costruzioni, G.U.R.I. 4/2/2008 n.29, 2008.

[45] I. Iervolino, C. Galasso, E. Cosenza, REXEL: computer aided record selection for code based seismic structural analysis, Bulletin of Earthquake Engineering, 8, 339-362, 2010. 